\title{
Mastite Bovina: Tratamento Convencional e Ação de Compostos Extraídos de Plantas
}

\section{Bovine Mastitis: Conventional Treatment and Action of Compounds Extracted from Plants}

\author{
Thâmela Alves*a; Maria Aparecida Moreira ${ }^{b}$
}

\begin{abstract}
âniversidade de Cuiabá, Programa de Pós-Graduação Stricto Sensu em Biociência Animal. MT, Brasil.

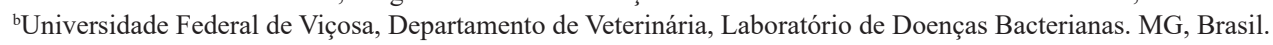
*E-mail: thamcristin@hotmail.com
\end{abstract}

\begin{abstract}
Resumo
A mastite bovina é a doença que mais onera a pecuária leiteira, por se tratar de uma doença plurietiológica e multifatorial, e altamente contagiosa. $\mathrm{O}$ uso de antimicrobianos ainda é a principal estratégia para controle e tratamento, todavia, a resposta à antibioticoterapia e o aumento de resistência bacteriana, bem como a presença de resíduos antimicrobianos no leite têm sido foco de estudos para definir quais os fatores responsáveis por falhas na terapia, além do estudo de várias substâncias extraídas de plantas como alternativas terapêuticas. Este artigo foi elaborado por meio de pesquisa bibliográfica, com o objetivo de abordar o uso de compostos naturais extraídos de plantas sobre bactérias isoladas em mastite bovina. Várias substâncias extraídas de plantas têm sido estudadas, para avaliação de suas atividades farmacológicas, gerando dados importantes e ótimos resultados. Grande destaque tem sido dado aos óleos essenciais, substâncias complexas, voláteis, lipofílicas, odoríferas e líquidas, oriundas do metabolismo secundário de vegetais e que têm despertado interesse como alternativa ao tratamento da mastite bovina. Diversos trabalhos têm comprovado a eficácia de compostos naturais extraídos de plantas sobre bactérias isoladas em mastite bovina, apresentando como estratégia terapêutica promissora, apesar de grande parte da diversidade genética vegetal do Brasil ainda permanecer oculta à ciência, merecendo a avaliação de suas propriedades farmacológicas.
\end{abstract}

Palavras-chave: Compostos Naturais. Pecuária Leiteira. Antimicrobiano.

\begin{abstract}
Bovine mastitis is the disease that burdens the most the dairy farming, due to the fact that it has many etiological reasons, and it is highly contagious. The use of antimicrobials is still the main strategy to control and treat this disease. However, the response to antibiotic treatment, the increase of bacterial resistance and the presence of antimicrobials residues in the milk as well, has been the main focus for researches to define which were the failure causes in the treatment, in addition to mentioning researches of many substances extracted from plants as alternative treatments. This article was written using bibliographic survey with the objective to discuss the use of natural compounds extracted from plants over cattle mastitis isolated bacteria. Many substances taken from plants have been studied for the proper evaluation of their pharmacological usage, resulting in the achievement of important data and great results. A considerable highlight has been given to the essential oils, complex, volatile, lipophilic, odoriferous and liquid substances originated from the plants secondary metabolism, and which have risen the interest as an alternative to the cattle mastitis treatment. Several researches have proved the efficiency of natural compounds extracted from plants over cattle mastitis isolated bacteria, proving to be a new promising therapeutic strategy, although most of the vegetal genetic diversity in Brazil is still hidden to science, thus deserving a proper evaluation of their pharmacological properties.
\end{abstract}

Keywords: Natural Compounds. Dairy Farming. Antimicrobial.

\section{Introdução}

A mastite bovina é a doença que mais onera a pecuária leiteira, por se tratar de uma doença plurietiológica e multifatorial (ACOSTA et al., 2016; QUADROS et al., 2019). Em grande parte dos casos, as causas estão associadas à agentes bacterianos, que invadem o canal do teto e se instalam nos tecidos mamários se multiplicando e, induzindo à inflamação (PERES NETO; ZAPPA, 2011). Entre os prejuízos estão a queda da produção leiteira, o descarte do animal por acometimento do parênquima mamário, descarte do leite de animais em tratamento e a redução da qualidade do leite, inviabilizando seu processamento (SANTOS; FONSECA, 2007; LANGONI et al., 2011).
$\mathrm{Na}$ mastite contagiosa bactérias como Staphylococcus aureus e Streptococcus agalactiae são as mais prevalentes, pois permanecem no interior da glândula mamária (PERES NETO; ZAPPA, 2011; KEEFE et al., 2011; ACOSTA et al., 2016). Também são agentes importantes as enterobactérias Escherichia coli, Klebsiella spp e Enterobacter spp, (SILVA et al., 2010; LANGONI et al., 2017), bem como Streptococcus bovis, Streptococcus dysgalactiae e Streptococcus uberis, considerados agentes causadores de mastites ambientais (SOMMERHAUSER et al., 2003; SCHUKKEN et al., 2014). A transmissão destes patógenos ocorre, especialmente, entre animais ou entre quartos mamários durante a ordenha (COSTA et al., 2017; LANGONI et al., 2011).

$\mathrm{O}$ uso de medicamentos antimicrobianos ainda é a 
principal estratégia para tratamento da mastite, comumente são empregadas drogas como penicilinas, estreptomicina, cefalosporina e tetraciclina (BEURON, 2014). As cefalosporinas têm sido amplamente utilizadas no tratamento das mastites, independente do micro-organismo causador (LANGONI et al., 2017). Porém, o principal entrave, além da resposta animal, em função do patógeno causal, é o resíduo do antimicrobiano no leite, devendo-se descartar o leite no período do tratamento (FERNANDES, 2019). A resposta insatisfatória à antibioticoterapia e o aumento de resistência bacteriana, sobretudo por $S$. aureus, tem sido foco de muitos estudos no esforço de determinar quais os fatores responsáveis por falhas na terapia, de modo que os tratamentos sejam mais efetivos no futuro (CORRÊA, 2018; FERNANDES, 2019; FANIN et al., 2020).

Nesse cenário, várias substâncias extraídas de plantas têm sido estudadas como alternativas terapêuticas (POZZO et al., 2011; MILLEZI et al., 2014), tornando-se candidatas ao desenvolvimento de novos agentes antimicrobianos (MIRANDA et al., 2015; BARROS et al., 2017). Nas últimas décadas, inúmeras pesquisas foram desenvolvidas usando várias partes de plantas (raiz, caule, folhas, flores e frutos) para avaliar suas atividades farmacológicas, gerando dados importantes e ótimos resultados, sobretudo, para ações antiinflamatórias, antineoplásica, anti-hipertensiva, antiarrítmica, analgésicas e antimicrobiana (MAIA, 2016; CORRÊA, 2018).

Este artigo tem como objetivo apresentar alterações decorrentes da mastite bovina, avaliar ação de tratamentos convencionais e compostos naturais extraídos de plantas sobre bactérias isoladas em mastite bovina.

\section{Desenvolvimento}

\subsection{Metodologia}

Trata-se de uma pesquisa indireta, elaborada por meio de pesquisa bibliográfica, com a proposta de abordar novos estudos sobre a mastite bovina e substâncias utilizadas como alternativa para o tratamento desta infecção, amparada em referências teóricas publicadas, por meio de periódicos científicos em bases de dados como SciELO, Pubmed, Portal Periódicos Capes e Google Acadêmico, publicados entre os anos de 2003 a 2020. Após a acessibilidade do trabalho na íntegra, foram selecionados os estudos de maior relevância para a temática.

Desse modo, foram selecionados trinta e cinco estudos com texto completo disponível, publicados em território nacional e internacional, utilizando como palavras-chave: mastite; bactérias isoladas, substâncias extraídas de plantas; antimicrobianos, individualmente e cruzadas entre si.

\subsection{A mastite bovina e suas repercussões na produção leiteira}

A pecuária leiteira, no território brasileiro, representa um papel econômico de alta significância, haja vista que se trata de um país com reconhecido potencial de exportação de leite para o mercado mundial, assim como exibindo um relevante papel no fornecimento de alimentos e na geração de empregos ao longo dessa cadeia produtiva (ZOCCAL et al., 2008; MAIA, 2016). No entanto, a diversidade no padrão de produção e a alta prevalência de mastite nos rebanhos leiteiros ainda se configuram como fatores impeditivos para uma ascensão desenvolvimentista da atividade leiteira nacional (LEITE, 2016).

A produção leiteira brasileira não possui um padrão (MAIA, 2016), visto que é realizada tanto em pequenas propriedades com produção de subsistência, quanto nas grandes propriedades com produção de larga escala, nas quais do ponto de vista tecnológico, no primeiro caso, as técnicas de produção são subutilizadas ou até mesmo ausentes, enquanto no segundo caso são empregadas avançadas tecnologias, tendo em vista o aperfeiçoamento da produção, bem como assegurar a obtenção de um produto final sanitariamente controlado (ZOCCAL et al., 2008; QUADROS et al., 2019).

Entre os diversos fatores relacionados com a baixa produtividade leiteira se destacam as condições sanitárias dos rebanhos (SILVA et al., 2010; LEITE, 2016), sendo justamente nessa questão que se enquadra a mastite bovina. A referida doença é um dos principais males que acometem a bovinocultura leiteira, definida como um processo inflamatório da glândula mamária, de origem infecciosa ou não, que atinge a mucosa, o tecido secretor e/ou intersticial da glândula mamária (SANTOS; TOMAZI; GONÇALVES, 2011; ACOSTA et al., 2016; LANGONI et al., 2017).

$\mathrm{Na}$ maior parte dos casos, as causas da mastite se encontram associadas à agentes bacterianos, os quais invadem a glândula mamária por meio do canal do teto e, então se instalam nos tecidos mamários, nos quais se multiplicam e, por consequência, induzem à inflamação (PERES NETO; ZAPPA, 2011; MAIA, 2016). O desencadeamento do processo inflamatório, na realidade, é a resposta gerada pelo sistema imune do animal, visando a eliminação do agente causador, neutralização das toxinas produzidas, e também a regeneração dos tecidos lesionados (SANTOS; FONSECA, 2007; KEEFE et al., 2011).

Em razão do processo inflamatório há aumento da permeabilidade vascular, e os componentes do plasma sanguíneo são misturados ao leite, alterando seu equilíbrio iônico e outras propriedades sensoriais (SANTOS; TOMAZI; GONÇALVES, 2011; LEITE, 2016). Ademais, uma vez lesionados pela inflamação, a quantidade de alvéolos pode reduzir, havendo também redução da capacidade de secreção de leite, levando à diminuição leiteira entre $10 \%$ à $30 \%$ (PERES NETO; ZAPPA, 2011). A substituição das células epiteliais secretoras por tecido conjuntivo, pode ser uma das consequências da mastite, causando a perda da capacidade produtiva (SOMMERHAUSER et al., 2003).

Por se tratar de uma doença plurietiológica e multifatorial, 
a mastite é uma das principais responsáveis por causar perdas na indústria leiteira (ACOSTA et al., 2016; QUADROS et al., 2019). Entre os principais prejuízos acarretados pela doença estão a queda expressiva da produção leiteira, o descarte de vacas pelo acometimento do parênquima mamário, a desvalorização comercial das mesmas, bem como os custos referentes à necessidade de diagnósticos microbiológicos, medicamentos e médico veterinário (SANTOS; FONSECA, 2007; SILVA et al., 2010; PERES NETO; ZAPPA, 2011).

Evidencia-se, ainda, os prejuízos ocasionados pelo descarte do leite dos animais em tratamento e a significativa diminuição da qualidade do leite em razão das alterações microbiológicas, físico-químicas e sensoriais, assim, inviabilizando o processamento do mesmo (SANTOS; FONSECA, 2007; MAIA, 2016). No que tange aos consumidores, a possível ingestão do leite proveniente de animais acometidos pela doença possibilita que determinados resíduos microbiológicos ou/e antimicrobianos possam ameaçar a saúde dos mesmos (SILVA; SILVA; RIBEIRO, 2012; OLIVER et al., 2020).

\subsection{Manifestação, diagnóstico e agentes infecciosos}

A mastite bovina pode ser classificada como clínica ou subclínica, de acordo com a sintomatologia dessa enfermidade. A mastite clínica é caracterizada pela visualização de sinais inflamatórios no leite e na vaca, a gravidade de sua manifestação pode ser classificada como leve, moderada e grave. $\mathrm{O}$ animal exibe alterações fisiológicas e também comportamentais, como tentativas de derrubar o conjunto de teteiras e menor tempo em decúbito, caracterizando desconforto e comprometimento do bem-estar (LEITE, 2016; LANGONI et al., 2017).

A mastite subclínica, por sua vez, não apresenta sinais clínicos evidentes, porém é caracterizada pela redução da produção de leite, aumento da CCS (Contagem de Células Somáticas) e alteração da composição do leite. Há ainda o aumento da permeabilidade vascular e, por consequência, do influxo de células inflamatórias e da CCS (LANGONI et al., 2011). Além disso, há alteração nos componentes do leite, elevando as concentrações de proteínas séricas, reduzindo os teores de caseína, lactose e gordura (SOMMERHAUSER et al., 2003).

Cabe salientar que a mastite subclínica apresenta uma maior importância epidemiológica, haja vista que pode ocorrer disseminação do agente infeccioso entre animais dentro dos rebanhos, sem qualquer observação de alterações macroscópicas do leite ou do úbere (ACOSTA et al., 2016; LANGONI et al., 2017). Estudos epidemiológicos estimam que a mastite subclínica seja responsável por 90-95\% dos episódios da doença nos rebanhos, sendo 15 a 40 vezes mais prevalente que a clínica, embora sua prevalência seja subestimada, pois não exibe sintomas evidentes (SANTOS; FONSECA, 2007; COSTA et al., 2017).

Para diagnóstico da mastite clínica pode ser utilizado o método da caneca de fundo escuro, realizado pela inspeção dos três primeiros jatos de leite, contra um fundo preto. São indicativos de mastite: leite com grumos, mudança na coloração do leite, consistência mais aguada e, às vezes, presença de sangue ou pus. Este método é prático, e pode ser realizado com frequência, permitindo rápida identificação de animais acometidos (LEITE, 2016).

Na mastite subclínica, a detecção a campo, geralmente, é realizada por meio do teste rápido California Mastitis Test (CMT), identificando o processo inflamatório da glândula mamária pelo aumento de células somáticas (especialmente neutrófilos polimorfonucleares). Durante o teste, a liberação do material nuclear dos leucócitos leva ao aumento da viscosidade, caracterizando uma reação cuja interpretação depende da intensidade, podendo ser interpretada em termos de escores: negativo, suspeito, fracamente positivo, positivo e fortemente positivo, de 1 a 5 , respectivamente (TRONCO, 2010).

A higiene inadequada das mãos do ordenhador e do ambiente está relacionado à mastite subclínica, principalmente, causada por Staphylococcus coagulase negativo, enfatizando importância das boas práticas na prevenção da mastite (LANGE, 2017). Ainda podem ser citadas as bactérias do gênero Nocardia, como outros patógenos ambientais, entre essas a Nocardia asteroides, altamente contagiosa, ocasionando episódios isolados de mastite, ou até em forma de surtos (LANGONI et al., 2017). Neste grupo também se encontram as Pseudomonas aeruginosa, fungos, leveduras e algas do gênero Prototheca (PERES NETO; ZAPPA, 2011; SCHUKKEN et al., 2014), os quais são de difícil tratamento, levando a casos crônicos que, na maioria das vezes, acarretam a perda dos tetos afetados.

Embora sejam classificados como patógenos ambientais, algumas cepas de Streptococcus uberis e Streptococcus dysgalactiae, podem se comportar como contagiosas (KEEFE et al.,2011). Estudos descrevem que todas as espécies bacterianas causadoras de mastite podem apresentar transmissão contagiosa ou ambiental (SCHUKKEN et al., 2014).

\subsection{Tratamento convencional e substâncias extraídas de plantas como tratamento alternativo}

Os antimicrobianos são amplamente empregados para o tratamento de doenças infecciosas em animais e humanos, desde a década de 1940 com a introdução da penicilina. Ao longo dos anos, estudos relatam a resistência à antimicrobianos de agentes etiológicos causadores da mastite bovina (BARLOW, 2011; LEITE, 2016).

Essa resistência tem gerado infecções que não respondem às terapias convencionais. Em humanos, há relação com os antimicrobianos usados em animais de produção, pois certas bactérias resistentes podem ser transferidas ao humano pelo consumo, ou por resíduos de antimicrobianos na carne e leite, e seus derivados (OLIVER et al., 2020).

Em rebanhos nos quais houve o uso sistêmico de 
macrolideos, cefalosporinas de terceira geração e tetraciclinas, foi evidenciado o aumento da prevalência dos genes de resistência erm, bla ARL e tet. A presença desses genes de resistência aos referidos antimicrobianos é preocupante, pois são antimicrobianos usados no tratamento de humanos e de animais, o que enfatiza a necessidade de reduzir o uso dessas drogas (NOBREGA et al., 2018).

No Brasil, o cenário é mais grave, pois $25 \%$ do leite produzido não é industrializado em instalações de fiscalização oficial, e consumido sem tratamento térmico ou controle laboratorial (CORRÊA, 2018).

Nesse cenário, várias alternativas terapêuticas baseadas em substâncias extraídas de plantas têm sido estudadas como compostos bioativos (POZZO et al., 2011; MILLEZI et al., 2014); capazes de inibir o crescimento de patógenos ou matá-los, com toxicidade mínima às células hospedeiras (FERNANDES, 2019); inclusive tornando-se candidatos ao desenvolvimento de novos agentes antimicrobianos (MIRANDA et al., 2015; BARROS et al., 2017).

O Brasil possui uma vasta biodiversidade vegetal, porém grande parte ainda permanece oculta à Ciência. Nas últimas décadas, foram iniciadas inúmeras pesquisas usando plantas para avaliar suas atividades farmacológicas, gerando dados importantes e ótimos resultados, sobretudo, para ações antiinflamatórias, antineoplásica, anti-hipertensiva, antiarrítmica, analgésicas e antimicrobiana (MAIA, 2016; CORREA, 2018). As principais substâncias extraídas de plantas, com propriedades antimicrobianas incluem: polipeptideos, terpenoides, alcaloides, substâncias fenólicas e polifenóis (fenóis simples, ácidos fenólicos, quinonas, flavonas, flavonóis eflavonoides), taninos e cumarinas, em concentrações distintas, em que um composto farmacologicamente ativo é majoritário (POZZO et al., 2011; ROCHA, 2019; FANIN et al., 2020). Os óleos essenciais (OEs) extraídos de plantas condimentares e medicinais são um grupo de compostos bioativos, que têm despertado grande interesse como alternativa ao tratamento da mastite bovina associada à antimicrobianos (CASTRO et al., 2016). Os OE são substâncias complexas, voláteis, lipofílicas, odoríferas e líquidas, oriundas do metabolismo secundário de vegetais. São aplicados em vários segmentos, como antibacterianos, antivirais, antifúngicos, inseticidas e contra o ataque de herbívoros, e nos setores de higiene pessoal, perfumaria, cosmética (POZZO et al., 2011; MILLEZI et al., 2014).

As plantas do gênero Croton (Euphorbiaceae) são conhecidas por suas atividades anti-hipertensivas, anti-inflamatórias, antimaláricas, antimicrobianas, antiespasmódicas, antiulcerogênicas, antivirais e miorelaxantes comprovadas. Os óleos essenciais de Croton tetradenius Baill (OECT) e Croton pulegiodorus Baill (OECP) apresentaram sinergismo entre si e com antimicrobianos convencionais (oxacilina, ampicilina e benzilpenicilina) sobre isolados de $S$. aureus e esta ação antibacteriana pode ser uma alternativa natural para terapia também combinados com antimicrobianos (SALATINO, 2007; ROCHA, 2019). O OE extraído das folhas de Satureja montana e Citrus limonia apresenta efeito inibitório sobre E. coli e $S$. aureus respectivamente, e esta ação antibacteriana in vitro sugere o uso potencial destes óleos como uma alternativa aos antimicrobianos sintéticos (MILLEZI et al., 2014).

O óleo de capim - limão (Cymbopogon citratus) apresenta ação antimicrobiana contra patógenos encontrados na mastite bovina como $S$. agalactiae e $B$. cereus, sendo que $S$. aureus e $E$. coli são sensíveis a alguns dos seus componentes como citral e geraniol, além de inibir a formação e atuar na eliminação de biofilmes de $S$. aureus (AIEMSAARD et al., 2011).

O extrato etanólico (EE) das folhas de Montrichadia linifera (arruda) é um composto bioativo, com ação antibacteriana em bactérias Gram positivas (MIRANDA et al., 2015). A atividade antibacteriana in vitro é demonstrada por extratos etanólicos obtidos de Cymbopogon nardus, Senna macranthera, Artemisia absinthium, Baccharis dracunculifolia, estes são capazes de inibir o crescimento de $S$. aureus isolados de mastite bovina (DIAZ et al., 2010). Óleos de plantas condimentares como Origanum vulgare (orégano), Thymus vulgaris (tomilho), Lippia graveolens (lipia), Zingiber officinale (gengibre), Salvia officinalis (sálvia), Rosmarinus officinalis (alecrim) e Ocimum basilicum (manjericão) possuem efeitos em isolados de Staphylococcus spp, oriundos de rebanhos leiteiros bovinos (POZZO et al., 2011; FANIN et al., 2020).

Alpinia zerumbet, assim como diversas espécies medicinais, é rica em flavonoides que possuem atividade antimicrobiana, assim como o ácido elágico. O óleo essencial e o extrato etanólico das folhas de A. zerumbet exibem importante ação antimicrobiana contra Staphylococcus aureus, sendo, portanto, candidato a compostos antibacterianos para tratamento da mastite bovina (CASTRO et al., 2016).

Substâncias bioativas como 7-epiclusianona e seu complexo metálico 7-epiclusianona-cobre (7-epi-Cu), e gutiferona-A vêm mostrando como uma alternativa promissora para tratamento da mastite bacteriana, possuindo atividade antimicrobiana significativa sobre Streptococcus spp., Streptococcus uberis e Streptococcus agalactiae isolados de mastite bovina, além da segurança por não apresentarem efeitos citotóxicos sobre células da glândula mamária de bovinos (MAC-T) (MAIA, 2016; BARROS et al., 2017).

\section{Conclusão}

Diversos trabalhos têm comprovado a eficácia de compostos extraídos de plantas sobre bactérias isoladas em mastite bovina, apresentando como estratégia terapêutica promissora para tratamento de infecções, reduzindo o uso de antimicrobianos tradicionais e se adequando à abordagem de Saúde Única. O Brasil, além de possuir a maior biodiversidade do Mundo, representa a maior diversidade genética vegetal e, grande parte ainda permanece oculta à Ciência, merecendo a avaliação de suas propriedades farmacológicas. 


\section{Referências}

ACOSTA, A. C. et al. Mastites em ruminantes no Brasil. Pesq. Vet. Bras., v. 36, n. 7, p. 565-573. 2016. doi: 10.1590/S0100736X2016000700001.

AIEMSAARD, J. et al. The effect of lemongrass oil and its major components on clinical isolate mastitis pathogens and their mechanisms of action on Staphylococcus aureus DMST 4745. Res Vet Sci., v. 91, p.31-37, 2011. doi: 10.1016/j.rvsc.2011.01.012.

BARLOW, J. Mastitis therapy and antimicrobial susceptibility: a multispecies review with a focus on antibiotic treatment of mastitis in dairy cattle. J Mammary Gland Biol Neoplasia., v. 16, n. 4, p.383-407, 2011. doi: 10.1007/s10911-011-9235-z.

BARROS, M. et al. Antibacterial Activity of 7-Epiclusianone and Its Novel Copper Metal Complex on Streptococcus spp. Isolated from Bovine Mastitis and Their Cytotoxicity in MAC-T Cells. Molecules, v. 22, n. 823; p. 1-15, 2017. doi: 10.3390/ molecules22050823.

BEURON, D. C. et al. Fatores de risco associados à resistência antimicrobiana de Staphylococcus aureus isolado de mastite bovina. Pesq. Vet. Bras., v. 34, n.10, p.947-952, 2014. doi: 10.1590/S0100-736X2014001000004.

CASTRO, K. N. C. et al. Composição química e eficácia do óleo essencial e do extrato etanólico de Alpinia zerumbet sobre Staphylococcus aureus. Arq. Inst. Biol., v.83, p. 1-7, e0192014, 2016. doi: 10.1590/1808-1657000192014.

CORRÊA, C. S. S. Nanoprópolis no tratamento da mastite subclínica bovina: avaliação in vivo da eficácia via intramamária durante o período de lactação. 2018, 90p. Dissertação (Mestrado em Agroecossistemas). Universidade Federal de Santa Catarina, Florianópolis, 2018.

COSTA, H. N. et al. Estimativa das perdas de produção leiteira em vacas mestiças Holandês x Zebu com mastite subclínica baseada em duas metodologias de análise. Arq. Bras. Med. Vet. Zootec., v. 69, p.579-586, 2017. doi: 10.1590/1678-4162-9019.

DIAZ, M. A. N. et al. Triagem de plantas medicinais para atividades antibacterianas em cepas de Staphylococcus aureus isoladas de mastite bovina. Rev. Bras. Farmacogn., v. 20, n. 5, p. 724-728, 2010 doi: 10.1590/S0102-695X2010005000013.

FANIN, M. et al. Métodos alternativos no tratamento de infecções causadas por Staphylococcus aureus. Med. Vet., v.14, n.1, p.2432, 2020. doi: 10.26605/medvet-v14n1-3711

FERNANDES, F. C. Avaliação do potencial antimicrobiano do decocto da folha do cajá (Spondias mombin L.) na prevenção da mastite bovina. Mossoró: Universidade Federal Rural do SemiÁrido, 2009..

KEEFE, G. et al. Using on-farm mastitis culturing. WCDS Advances in Dairy Technology, n.23, p.81-91, 2011.

KÖCHE, J. C. Fundamentos de metodologia científica: teoria da ciência e iniciação à pesquisa. Petrópolis: Vozes, 2013.

LANGE, M. J. et al. Tipologia de manejo de ordenha: análise de fatores de risco para a mastite subclínica. Pesq. Vet. Bras., v.37, n.11, p.1205-1212, 2017. doi: 10.1590/s0100736x2017001100004.

LANGONI, H. et al. Aspectos microbiológicos e de qualidade do leite bovino. Pesq. Vet. Bras., v.31, n.12, p.1059-1065, 2011. doi: 10.1590/S0100-736X2011001200004.

LANGONI, H. et al. Considerações sobre o tratamento das mastites. Pesq. Vet. Bras., v.37, n.1, p.1261-1269, 2017. doi: 10.1590/s0100-736x2017001100011.
LEITE, R. F. Concentração inibitória mínima de extratos brutos produzidos por actinobactérias para agentes causadores de mastite bovina. Pirassununga: Universidade de São Paulo, 2016.

MAIA, N. L. Potencial antimicrobiano de substâncias extraídas do fruto de Garcinia brasiliensis sobre isolados de Streptococcus spp. obtidos de mastite. Viçosa: Universidade Federal de Viçosa, 2016.

MIRANDA, J. A. et al. Atividade antibacteriana de extratos de folhas de Montrichardia linifera (Arruda) Schott (Araceae). Rev. Bras. Pl. Med., v.17, n.4, p.1142-1149, 2015. doi: 10.1590/1983084X/14_169.

MILLEZI, A. et al. Caracterização e atividade antibacteriana de óleos essenciais de plantas condimentares e medicinais contra Staphylococcus aureus e Escherichia coli. Rev. Bras. Pl. Med., v.16, n.1, p.18-24, 2014. doi: 10.1590/S151605722014000100003 .

NOBREGA, D. B., DE BUCK, J., BARKEMA, H. W. Antimicrobial resistance in nonaureus staphylococci isolated from milk is associated with systemic but not intramammary administration of antimicrobials in dairy cattle. J. Dairy Sci., v.101, ed. 8, p.7425-7436, 2018. doi: 10.3168/jds.2018-14540.

OLIVER, J. P. et al. Invited review: Fate of antibiotic residues, antibiotic-resistant bacteria, and antibiotic resistance genes in US dairy manure management systems. J. Dairy Sci., v. 103, n. 2, 2020. doi: $10.3168 /$ jds.2019-16778

PERES NETO, F.; ZAPPA, V. Mastite em vacas leiteiras - revisão de literatura. Rev. Cient. Eletr. Med. Vet., v.16, p.1679-7353, 2011.

POZZO, M. D. et al. Atividade antimicrobiana de óleos essenciais de condimentos frente a Staphylococcus spp. isolados de mastite caprina. Ciênc. Rural, v.41, n.4, p.667-672, 2011. doi: 10.1590/ S0103-84782011005000029.

QUADROS, D. G. et al. Maior nível tecnológico e escala de produção propiciam melhor qualidade do leite e menor ocorrência de mastite bovina? Rev. Acad.: Ciênc. Animal, v.17, p.1-13, 2019. doi: 10.7213/1981-4178.2019.1700.

ROCHA, R. R. Estudo comparativo sobre a composição química, atividade microbiana e efeito sinérgico dos óleos essenciais de Croton tetradenius Baill. e C. pulegiodorus Baill., contra isolados de Staphylococcus aureus. Sobral: Universidade Federal do Ceará, 2019.

SALATINO, A.; SALATINO, M. L. F.; NEGRI, G. Usos tradicionais, química e farmacologia de espécies de Croton (Euphorbiaceae). J. Braz. Chem. Soc., v.18, n.1, p.11-33, 2007. doi: 10.1590/S0103-50532007000100002.

SANTOS, M.V.; FONSECA, L. F. L. Estratégias para controle de mastite e melhoria da qualidade do leite. São Paulo: Manole, 2007.

SANTOS, M.V.; TOMAZI, T.; GONÇALVES, J. L. Novas estratégias para o tratamento da mastite bovina. Rev. de Vet. e Zootec., v. 18, p. 131-137, 2011.

SCHUKKEN, Y. et al. Efficacy of vaccination on Staphylococcus aureus and coagulase-negative staphylococci intramammary infection dynamics in 2 dairy herds. J. Dairy Sci., v. 97, n. 8, p. 5250-5264, 2014. doi: 10.3168/jds.2014-8008.

SILVA, M. V. M. et al. A mastite interferindo no padrão de qualidade do leite: uma preocupação necessária. Rev. Cient. Elet. de Med. Vet., Garça, ano 8, n. 14, p. 1-10, 2010.

SILVA, R.M.; SILVA, R.C.; RIBEIRO, A. B. Resíduos de antibióticos em leite. SaBios: Rev. Saúde Biol., v. 7, n.1, p.30-44, 2012. 
SOMMERHÄUSER，J. The epidemiology of Staphylococcus aureus infections from subclinical mastitis in dairy cows during a control program. Vet. Microbiol., v. 96, n. 1, p. 91 - 102, 2003. doi: 10.1016/s0378-1135(03)00204-9.

TRONCO, V.M. Manual para inspeção da qualidade do leite.
Santa Maria: UFSM, 2010.

ZOCCAL, R. Anova pecuária leiteira brasileira. In: CONGRESSO BRASILEIRO DE QUALIDADE DO LEITE. 2008, Recife, Anais.... Rede Brasileira de Qualidade do Leite, 2008. 